\title{
Using Segmented Standard Taxi Routes to Integrate Unmanned Aircraft Systems at Civil Airports
}

\author{
Michael Finke \\ Institute of Flight Guidance \\ German Aerospace Center (DLR) \\ Braunschweig, Germany \\ Michael.Finke@dlr.de
}

\author{
Nikolai Okuniek \\ Institute of Flight Guidance \\ German Aerospace Center (DLR) \\ Braunschweig, Germany \\ Nikolai.Okuniek@dlr.de
}

\begin{abstract}
Cargo airlines and other aircraft operating agencies are interested in commercially exploiting and benefiting from the technical possibilities provided by unmanned aircraft systems. Use cases could be long-range unmanned air transport, flight calibration, or surveillance missions. It is natural that, depending on weight and size, unmanned aircraft are going to use the existing ground infrastructure together with manned aircraft. However, it is also a well-known fact that remotely piloted or automatic / autonomous unmanned aircraft do not have the same abilities and behavior as manned aircraft. There is a need to achieve a safe, orderly and expeditious flow of a mixed traffic constellation even when more than one unmanned aircraft are involved in aerodrome operations at the same time. Unfortunately, due to a lack of international standardization and regulation, it is still unknown which abilities a commercial unmanned aircraft will have. This makes it very difficult to define operational procedures. In the frame of the SESAR 2020 project 'Surface Management Operations' (SuMO), a procedural concept for ground movements of unmanned aircraft together with manned aircraft was elaborated. This concept uses so called segmented standard taxi routes and aims at realizing mixed traffic with an equal level of safety compared to pure manned traffic as well as very low system requirements for unmanned aircraft systems. In November 2017, this concept was validated together with tower controllers, conventional pilots, remotely piloted aircraft operators and an air traffic management expert from the German Air Navigation Service Provider DFS in a gaming workshop over several days. The validation covered departures, arrivals and non-nominal situations like C2 link loss or lost communication. Results showed that this concept likely allows a fast and easy integration of unmanned aircraft systems. It was rated as very practical, realistic and acceptable in terms of safety, human performance and the key performance areas access and equity as well as interoperability.
\end{abstract}

Keywords-unmanned aircraft systems; aerodrome operations; integration; segmented standard taxi routes

\section{INTRODUCTION}

The term 'unmanned aircraft system' (UAS) stands for a wide range of different systems, from small camera drones, last mile parcel delivery systems and military reconnaissance systems up to not yet existing, but well imaginable wide-body unmanned cargo aircraft. The European Aviation Safety Agency (EASA) therefore distinguishes several categories of UAS including remotely piloted aircraft systems (RPAS), which will be the basis for future European regulations of such systems [1]:
- 'Open' category: Low-risk operations under direct visual line of sight; below $150 \mathrm{~m}$ above ground or water and outside of specified reserved areas.

- 'Specific' category: Operations requiring a safety risk assessment as well as specially trained staff and an authorization by the national aviation authority.

- 'Certified' category: Fully regulated operations comparable to conventional (piloted) aircraft.

For commercial use, especially in terms of air transport with unmanned aircraft, the 'specific' as well as the 'certified' category are preferable. Several advantages against comparable manned aircraft can be expected (beside others):

- Reduced operational costs;

- Higher level of flexibility;

- No limitation because of maximum crew times;

- Higher level of accuracy (due to a higher level of automation).

It can further be expected that especially the 'certified' category will need a suitable ground infrastructure comparable to the one used by manned aviation. The ideal case, which is desirable, would be a shared use of the existing airport installations by both, manned and unmanned aircraft.

\section{A. Challenges}

At the current stage of technology, RPAS do not have the same abilities and behavior as manned aircraft, including some essential capabilities. A short summary of challenges when introducing RPAS to aerodrome surface traffic is presented in this section.

\section{1) Detect / Sense and Avoid}

Basically, at an international airport, air traffic control (ATC) is responsible for preventing collisions between two aircraft or between an aircraft and other vehicles, persons or obstacles. This is done by giving appropriate taxi clearances as well as instructions to hold at specific points or to give way to other traffic [2]. However, even at a controlled aerodrome, taxiing manned aircraft must be able to see other traffic (other taxiing or towed aircraft or ground vehicles) and maintain a safe distance to them on their own in some cases. For example, this is important when there is other traffic in front of one 
particular aircraft which is moving slower or which is about to stop (e.g. because it is reaching a runway holding point).

In addition to that, there might be circumstances which can hardly be recognized by ATC, such as foreign objects, spills, contamination or damage on the taxiway. For this reason, the pilot of a manned aircraft shall always visually re-check that the taxiway is safely usable for the movement.

Presently, there is no RPAS technology available which is able to fully reproduce this capability of manned flights. In addition, there are no detailed regulations about the required performance of such systems in place.

2) Recognition of Signs and Signals

In manned aviation, several signs and signals are used at controlled aerodromes, such as (beside others) [3]:

- Runway and taxiway designators;

- $\quad$ Closed runways / taxiways marked with an ' $\mathrm{X}$ ';

- $\quad$ Restricted taxiways (e.g. restricted wing span);

- $\quad$ Red stop bar lights [4];

- $\quad$ Light gun signals [5];

- Light signals belonging to future taxi concepts, such as 'follow the greens' [6].

Manned aircraft must be able to recognize and consider these signs and signals. Presently, there is again no RPAS technology available which is able to fully reproduce this human capability with the same performance.

\section{3) Navigation on Ground}

In manned aviation the navigation during taxi movements is normally done with visual reference to the ground while yellow markings as well as taxiway edge / centerline lights are used as guidance by the pilot.

Currently, it is neither regulated nor technically required that unmanned aircraft also navigate with visual reference to the ground during self-powered taxi operations. Thus it is very likely that alternate means are used, e.g. satellite navigation. Therefore, the logical consequence is that the taxiway dimensions must match with the navigational performance of the unmanned aircraft on ground. Further, RPAS-specific technical installations supporting the RPAS ground movement may be required. It is likely that taxiway markings or taxiway lights are no longer needed for a ground movement of an RPAS.

\section{4) Compliance with ATC Clearances}

At controlled aerodromes all traffic on the maneuvering area including aircraft, vehicles or persons is controlled by ATC. For this purpose, ATC clearances and essential information are transmitted from the air traffic controller to pilots, which is then acknowledged and executed or considered.

Regarding RPAS, it is neither regulated nor well known which of the typical ATC clearances the RPAS can execute and which not, how long it takes until a clearance can be executed and what the primary communication channel between the air traffic controller and the remote pilot (who is located somewhere on ground and not on the airplane) will be. Best practice would be if remote pilots communicate with ATC via VHF radio voice communication in the same way as manned aircraft do, but this is far from certain.

\section{5) Priority Flights}

Aerodrome traffic can involve manned priority flights such as aircraft in an emergency situation, Search-and-Rescue flights, ambulance flights or government flights [7]. RPAS ground movements must be able to give way to these flights even with a very short pre-notification time.

\section{6) Non-Nominal Situations with RPAS}

The most feared event in the context of flight operations with RPAS is a loss of the C2 link between the remote pilot station and the remotely piloted aircraft. In such a situation, the remote pilot no longer has control over or awareness about the status and manoeuvers of the airplane. The management of the flight would then be taken over by installed on-board systems and the flight would be continued automatically or even autonomously as far as possible. In this mode the RPAS movement becomes unpredictable and uncontrollable for air traffic controllers, for other pilots and aerodrome personnel. This constitutes a considerable safety risk in mixed traffic, where manned aircraft are operating next to unmanned aircraft.

\section{B. Today's Situation ('Baseline')}

Most of today's effective regulations concerning RPAS are focused on small systems of the EASA category 'Open' or 'Specific' while there are very few regulations for commercially used systems of the EASA category 'certified'. Currently, only military systems of this category have become operational, especially in combat areas where aviation laws play a minor role.

However, the idea of the existing concept of special activity areas (SAA) seems to be applicable when transferred to RPAS ground operations as a first approach. According to [8], a special activity area is 'an airspace of defined dimensions within which unusual VFR activities require special alertness by pilots for the safe conduct of flight'. ATC issues clearances to authorized flights to enter the SAA while all other VFR flights should avoid this area and all other IFR flights are separated from this area.

The same idea applied to ground operations would result in a full segregation of the RPAS taxi movement while no other RPAS or manned aircraft are allowed to operate at the same time on the same aerodrome or the same part of it. In practical words, conventional aerodrome traffic would be temporarily suspended to enable the RPAS movement. Afterwards, as soon as the RPAS movement is no longer a safety risk, normal operations would be resumed. Later on, this situation is referred to as Baseline $I$.

Another approach would be to simply tow the RPA from the stand to the runway while the driver of the towing truck takes over the full responsibility and replaces the missing capabilities of the RPAS. The detachment of the aircraft from the towing truck in case of departures as well as the attachment to the towing truck in case of arrivals would take place at the 
runway holding point / on the runway exit taxiway. Later on, this procedure is referred to as Baseline II. It was confirmed by two military RPAS pilots as one standard operational procedure used for military RPAS flights.

\section{SuMO project}

The SuMO (Surface Management Operations) project is one of the industrial research projects of the current SESAR 2020 program for the period from 2016 through 2019. The German Aerospace Center (DLR) is involved in this program through the AT-One consortium together with the Nationaal Lucht- en Ruimtevaartlaboratorium (NLR), the Dutch National Aerospace Laboratory. The main objectives of the SuMO project are to improve the predictability of airport surface operations and to increase the situational awareness of all relevant stakeholders. Furthermore, the integration of remotely piloted aircraft systems into airport surface operations shall be facilitated. DLR is involved in the work package 'Surface Operations by RPAS', where the work presented in this paper stems from and which is dedicated to facilitate the operation of RPAS at airports and their integration into an environment which is dominated by manned aviation. This work package aims to investigate ways in which RPAS may be able to use a technical capability or procedural means to comply with ATC instructions during surface operations.

\section{APPROACH}

The goal of the work described in this paper was to achieve a fast-and-easy integration of RPAS into controlled aerodrome traffic while maintaining the same level of safety compared to pure manned aerodrome traffic. The solution is intended to have an acceptable impact on human factors like workload and situational awareness and ensure a high level of access and equity for all aerodrome users. The focus of this work was on a quick and simple implementation with no or only minor changes to existing procedures and onboard equipment on board of all involved aircraft and for air traffic control. The method of integrating RPAS into aerodrome traffic has to be compatible with current aviation standards and priority was given on feasibility. In addition, the technical requirements to RPAS and the need to modify the aerodrome infrastructure shall be as low as possible. The solution shall further provide safety nets in case of unforeseen events such as lost communication and lost C2 link.

The German Aerospace Center (DLR) developed a procedural concept to achieve this, which is deduced and described in the following subsections.

\section{A. Abstraction of Taxi Movements}

From scientific point of view, a ground movement of an airplane has three 'parameters':

- A route consisting of waypoints and/or turns, which describes the lateral movement;
- Taxi speed $^{1}$, which describes the longitudinal movement along a route;

- Time constraints.

Basically, all three 'parameters' of a ground movement could be used for managing and de-conflicting the whole aerodrome traffic.

These 'parameters' can be assigned in the following ways:

- Assignment by an external decision maker (who is not involved in 'piloting' the RPAS as such, for example an air traffic controller) while the specifications are transferred via voice or datalink communication, via light signals or electronic beacons or via guidance vehicles.

- Procedural (specifications are written down in a published procedure).

- Autonomous (the aircraft and/or its pilot decide on their own according to the circumstances).

It is imaginable, that also a combination of these methods of assignment can be used.

\section{B. Parameter Matrix}

The next step is to establish a matrix which confronts both, the different parameters themselves and the methods of assignment, with each other. This matrix can be found in Table 1. Text in italic font represents examples how the corresponding combination is already used today or will be used in the near future.

\section{Derivation of Segmented Standard Taxi Route Procedure}

This matrix can be seen as a general framework for all conceivable taxi procedures, regardless if performed with manned or unmanned aircraft. Further, it points to alternative ways to define new procedures for special purposes, such as integrating RPAS into controlled aerodrome traffic.

The taxi procedure proposed in this paper is designed in the following way:

- Lateral Movement: Procedural,

- Longitudinal Movement: Procedural,

- Timing:

$$
\begin{array}{cl}
\circ & \text { External - Voice } \\
\circ & \text { External - Datalink } \\
\circ & \text { External - Signs/Beacons. }
\end{array}
$$

\footnotetext{
${ }^{1}$ A stop within an assigned route is understood as a temporary speed assignment of $0 \mathrm{kts}$
} 
TABLE 1. PARAMETER MATRIX FOR GROUND MOVEMENTS

\begin{tabular}{|c|c|c|c|}
\hline & $\begin{array}{l}\text { Lateral Movement (Route / Re- } \\
\text { Route) }\end{array}$ & Longitudinal Movement (Speed) & Time constraints \\
\hline $\begin{array}{l}\text { Autonomous } \\
\text { (Decision by the } \\
\text { aircraft / pilot) }\end{array}$ & $\begin{array}{l}\text { Aircraft / pilot decides on its /his own } \\
\text { about the route. } \\
\text { Not applicable at a controlled } \\
\text { aerodrome }\end{array}$ & $\begin{array}{l}\text { Aircraft / pilot decides on its / his own } \\
\text { about the speed. } \\
\text { Today's situation: Stop / Brake in } \\
\text { regard to other aircraft, e.g. in an } \\
\text { aircraft queue; requires Detect \& } \\
\text { Avoid capability }\end{array}$ & $\begin{array}{l}\text { Aircraft / pilot decides on its / his own } \\
\text { about the time when the taxi process is } \\
\text { commenced (without any trigger). } \\
\text { Not applicable at a controlled } \\
\text { aerodrome }\end{array}$ \\
\hline External - Voice & $\begin{array}{l}\text { Route is assigned via voice } \\
\text { communication by an external decision } \\
\text { maker. } \\
\text { Today's situation: Taxi clearances by } \\
\text { ATC }\end{array}$ & $\begin{array}{l}\text { Speed is assigned via voice } \\
\text { communication by an external decision } \\
\text { maker. } \\
\text { Today's situation: hold short of / } \\
\text { continue instructions by ATC }\end{array}$ & $\begin{array}{l}\text { The time when the taxi process is to be } \\
\text { commenced is assigned via voice } \\
\text { communication by an external decision } \\
\text { maker. } \\
\text { Today's situation: Taxi clearances by } \\
\text { ATC (it is expected that the taxi } \\
\text { process starts very soon after the } \\
\text { transmission of the taxi clearance) }\end{array}$ \\
\hline External - Datalink & $\begin{array}{l}\text { Route is assigned via data link by an } \\
\text { external decision maker. } \\
\text { Not yet used }\end{array}$ & $\begin{array}{l}\text { Speed is assigned via data link by an } \\
\text { external decision maker. } \\
\text { Not yet used }\end{array}$ & $\begin{array}{l}\text { The time when the taxi process is to be } \\
\text { commenced is assigned via data link by } \\
\text { an external decision maker. } \\
\text { Not yet used }\end{array}$ \\
\hline $\begin{array}{l}\text { External - Signs / } \\
\text { Beacons }\end{array}$ & $\begin{array}{l}\text { Route is assigned via light signals / } \\
\text { beacons by an external decision maker. } \\
\text { Follow the Greens }\end{array}$ & $\begin{array}{l}\text { Speed is assigned via light signals / } \\
\text { beacons by an external decision maker. } \\
\text { Stop bars in Cat II/III operations; } \\
\text { Follow the Greens }\end{array}$ & $\begin{array}{l}\text { The time when the taxi process is to be } \\
\text { commenced is assigned via light } \\
\text { signals / beacons by an external } \\
\text { decision maker. } \\
\text { Light gun signals by ATC (rarely used } \\
\text { in special cases) }\end{array}$ \\
\hline $\begin{array}{l}\text { External - Guidance } \\
\text { Vehicle }\end{array}$ & $\begin{array}{l}\text { Route is assigned by a guidance } \\
\text { vehicle. } \\
\text { Today's situation: Follow me / Towing } \\
\text { truck }\end{array}$ & $\begin{array}{l}\text { Speed is assigned by a guidance } \\
\text { vehicle. } \\
\text { Today's situation: Follow me / Towing } \\
\text { truck }\end{array}$ & $\begin{array}{l}\text { The time when the taxi process is to be } \\
\text { commenced is assigned by a guidance } \\
\text { vehicle. } \\
\text { Today's situation: Follow me / Towing } \\
\text { truck }\end{array}$ \\
\hline Procedural & $\begin{array}{l}\text { The route is prescribed by published } \\
\text { procedures / regulations / } \\
\text { announcements. } \\
\text { Standard taxi routes, e.g. Antalya } \\
\text { airport }\end{array}$ & $\begin{array}{l}\text { The speed is prescribed by published } \\
\text { procedures / regulations / } \\
\text { announcements. } \\
\text { Not yet used }\end{array}$ & $\begin{array}{l}\text { The time when the taxi process is to be } \\
\text { commenced is prescribed by published } \\
\text { procedures / regulations / } \\
\text { announcements. } \\
\text { Not yet used }\end{array}$ \\
\hline
\end{tabular}

In detail,

- The taxi route for an unmanned aircraft from every parking spot (which is approved to be used by RPAS) to every runway (which is approved to be used by RPAS) is standardized (see red line in Fig. 1),

- These routes are published and available for all aerodrome users,

- All standard RPAS taxi routes contain 'mandatory stop points', which split up the taxi route in defined segments (see black dots in Fig. 1),
- An external decision maker (i.e. ATC) issues one 'go'-command per route segment. This 'go'command is given at or short before reaching a 'mandatory stop point' for the next segment only. ATC has to ensure that, at the time when the 'go'command is given, the cleared segment is free of other aerodrome traffic and will remain clear of other aerodrome traffic.

- Only one RPA per route segment. 
It is not further specified which communication channel is to be used to transmit the 'go'-command from ATC to the pilot as this is of minor importance for the whole concept.

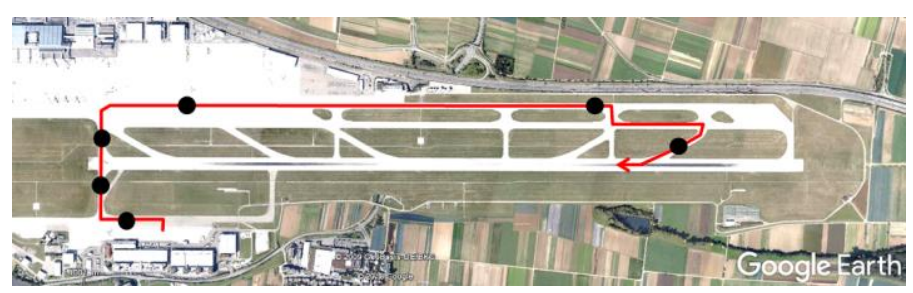

Fig. 1. Example for a possible segmented standard taxi route for Stuttgart Airport (Parking at Cargo South, Departure on runway 25)

\section{Supplementary Proposals}

The following measures and principles are proposed to support the procedure described before:

- The design of the segmented standard taxi routes should follow the one-way-principle as far as possible.

- Taxiway usability shall be linked with the navigational performance of the RPAS.

- Segmented standard taxi routes shall be checked regularly by the aerodrome operator similar to usual regular runway checks [9].

- $\quad$ All RPAS taking part in mixed manned and unmanned aerodrome traffic shall have special color schemes or markings to enable other pilots, tower controllers and ground personnel to identify the RPAS as such on the first look.

- In case of contingency, the RPAS shall show conspicuous flashing lights to enable other pilots, tower controllers and ground personnel to immediately recognize the situation even if the remote pilot is completely cut off.

\section{E. Expected Advantages and Disadvantages}

The following advantages of this procedure compared to Baseline I or Baseline II are expected:

- This concept allows an easy integration of RPAS into manned aerodrome traffic.

- $\quad$ The procedure is very simple and very definite.

- $\quad$ The traffic flow should be more fluid and expeditious compared to Baseline I or Baseline II.

- Basically, RPAS do not need a Detect-and-Avoidcapability for ground movements.

- The procedure provides a high transparency of the unmanned traffic to other pilots, air traffic controllers or ground personnel.

- ATC is able to manage the traffic because all aerodrome traffic is under control and at least basic means are available to influence the RPAS movements.
- In case of a loss of communication or a loss of C2 link, the aircraft would stop at the next mandatory holding point in any case, which guarantees that safety is maintained.

The following disadvantages of this procedure are expected:

- This procedure may need a higher level of attention on ATC side as traffic de-conflicting with RPAS is done by the controllers only.

- Traffic efficiency will be lower compared to pure manned traffic as there are only restricted options to guide unmanned traffic.

\section{VALIDATION METHODOLOGY}

To validate the proposed taxi procedures a dedicated validation workshop was held by DLR on $21^{\text {st }}-23^{\text {rd }}$ November 2017 at DLR premises in Cologne, Germany. Several professionals representing stakeholders or aerodrome traffic participants took part and provided valuable feedback from their perspective. The workshop was attended by two conventional airline pilots, two tower controllers (one from the German Air Navigation Service Provider DFS and one military air traffic controller with experience regarding RPAS operations at aerodromes), one additional air traffic management expert from DFS, and two remotely piloted aircraft operators (Heron) from the German Air Force. The latter selection was done to integrate the military as quite experienced user of remotely piloted aircraft operations. The workshop was led by an ATM researcher and validation expert from DLR.

The maturity phase of the SuMO project is currently 'V1' according to the European Operational Concept Validation Methodology (E-OCVM), which is why the validation techniques 'judgmental techniques' and 'gaming' were selected [10]. The workshop therefore was in principle a gaming session where mixed aerodrome traffic situations were 'played' and the participants had to elaborate the next steps and make decisions from their professional point of view. This was supplemented by judgmental techniques, which include interviews with and collects opinions of these subject matter experts.

Three different scenarios were used in the workshop:

- Arrival and Departure of the RPAS flight in Baseline I: full segregation of the RPAS ground movement,

- Arrival and Departure of the RPAS flight in Baseline II: the RPAS ground movement is done by towing the aircraft from / to the runway,

- Arrival and Departure of the RPAS flight using segmented standard taxi routes in nominal conditions,

Each scenario was evaluated while assuming the following conditions:

- nominal conditions, 
- contingency situation involving a loss of communication of the RPAS flight with ATC,

- contingency situation involving a loss of $\mathrm{C} 2$ link oft he RPAS.

The sessions were supported with short descriptions of the procedures to be applied as well as animated presentations to explain the respective scenarios and the concept of segmented standard taxi routes. Thereafter, scenarios were played through while feedback, comments and improvements from the participants were collected by making notes.

Every session was finished with a questionnaire that was adapted and tailor-made for the respective representative of the relevant stakeholder: conventional pilot, remote pilot or air traffic controller. The ATM expert from the DFS also received the questionnaires designed for the air traffic controllers. The questions comprise the key performance areas (KPA) safety, access and equity as well as interoperability. In addition, the human performance KPA was covered by using the standardized questionnaires 'Situational Awareness for SHAPE $^{2}$ (SASHA)', the 'SHAPE Automation Trust Index (SATI)' and 'Assessing the Impact of Automation on Mental Workload (AIM-s)' [11]. The AIM-s questionnaire is designed to be filled out by air traffic controllers only.

In addition, every participant was asked to give a personal estimation on the level of safety, access and equity, interoperability and the level of performance of a human operator using the corresponding procedures on a scale from 1 (worst imaginable) to 10 (best imaginable) after every session.

The workshop finally ended with asking the participants to give a ranking which procedure they would prefer to be used in aerodrome ground traffic.

\section{RESULTS}

This paper presents selected results from the workshop. Complete and detailed results focused on the individual KPA will be published elsewhere from summer 2018 on. Due to the relatively low number of participants, small differences between the individual ratings should not be over-interpreted.

\section{A. KPA Safety}

Besides filling tailor-made questionnaires, the participants were asked to estimate the level of safety of both baseline scenarios and the segmented standard taxi route scenario on a scale from 1 (not safe) to 10 (very safe). At this validation phase, values of 7 or above are considered as acceptable. The results are displayed in Figure 2.

It can be seen that in average all three solutions have the same estimated level of safety, which was one goal of this validation activity. ATC rates Baseline I scenario as the safest solution because manned and unmanned traffic are totally separated.

Baseline II was rated by ATC as less safe than Baseline I or segmented standard taxi routes, because this scenario significantly increases the vehicle traffic on the maneuvering

\footnotetext{
${ }^{2}$ SHAPE $=$ Solutions for Human Automation Partnerships in European ATM
}

area. In contrast, conventional (CP) and remote pilots (RP) rate the Baseline II scenario as the safest because they are used to aircraft being towed.

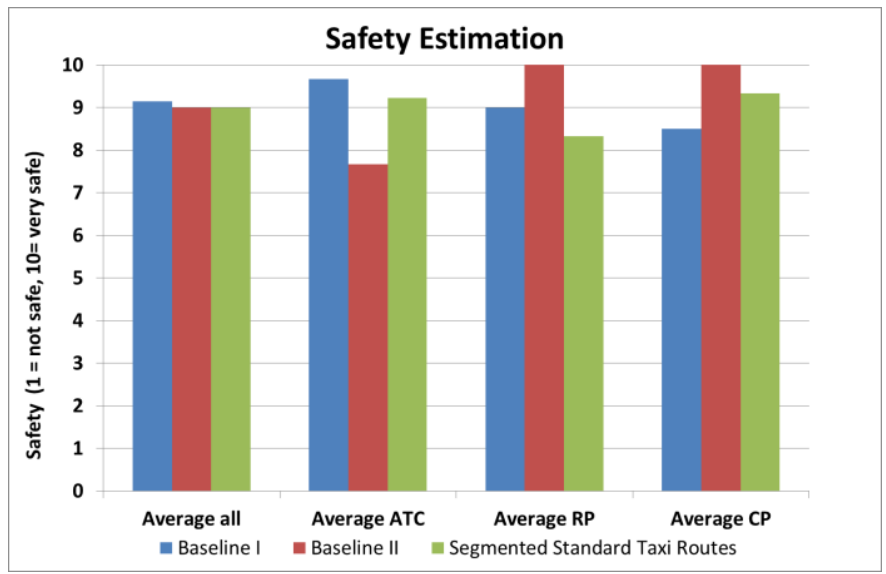

Fig. 2. Results for level of safety estimation

\section{B. KPA Access and Equity}

The participants were also asked to give a rating to which extent all aircraft, regardless if manned or unmanned, have an equal access to the aerodrome ground infrastructure and services and if they are treated equally $(=10)$ or maximally detrimental $(=1)$ for all three scenarios. At this validation phase, values of 7 or above are considered as acceptable. Due to the relatively low number of participants, small differences between the individual ratings should not be over-interpreted. The results are displayed in Figure 3.

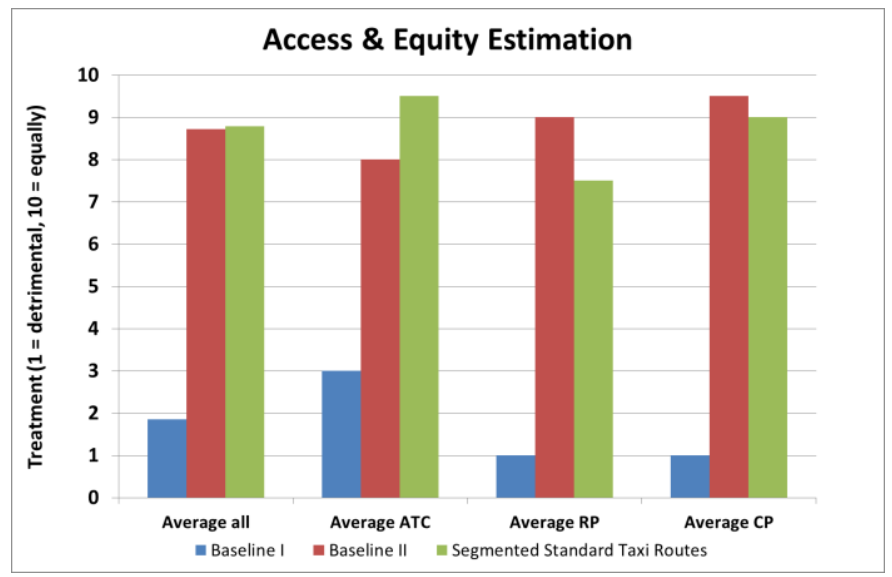

Fig. 3. Results for level of access and equity estimation

It can be seen that Baseline I scenario is rated as worst by all participants because in this scenario the aerodrome would be 'reserved' either for manned flights or for one single RPAS flight. ATC rated the segmented standard taxi route concept as best in terms of access and equity. The remote pilots rated Baseline II as best while the segmented standard taxi route concept also got an acceptable, but lower rating because they feel more restricted for ground movements with this solution. In average, the new procedure achieved a high level of access and equity, which was another goal of this validation activity. 


\section{KPA Interoperability}

For the KPA Interoperability the participants were asked how they estimate the compatibility of all three scenarios with current procedures and the airport infrastructure, or, on the other hand, the needed effort to adapt existing standards and installations to them: full compatibility / no effort (10) or no compatibility / maximum effort (1). At this validation phase, values of 7 or above are considered as acceptable. Due to the relatively low number of participants, small differences between the individual ratings should not be over-interpreted. Results are displayed in Figure 4.

It can be seen that baseline II scenario was rated as the best in average by all participants. This was more or less expected because towing operations is a known and common procedure. The ratings of the conventional pilots and air traffic controllers showed almost no difference between baseline II and segmented standard taxi routes.

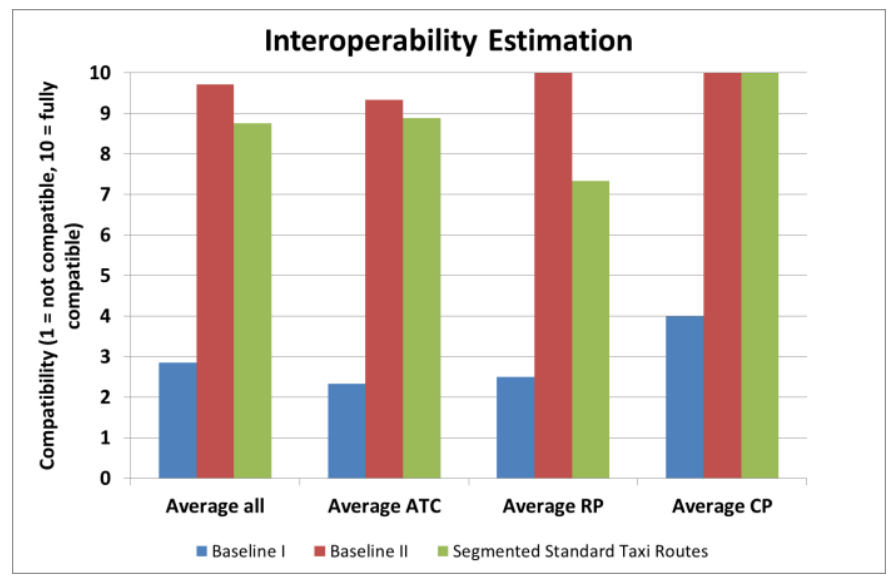

Fig. 4. Results for level of interoperability estimation

The rating of the remote pilots was - according to their statements - very conservative. The low rating of segmented standard taxi routes compared to baseline II was justified with the large number of factors and aspects influencing the level of interoperability. Therefore, a more detailed analysis involving different validation methods (e.g. real-time human in the loop simulation) is desirable. In sum the ratings regarding interoperability for the segmented standard taxi route procedure are acceptable.

\section{KPA Human Performance}

For the KPA Human Performance the participants were asked how they roughly estimate the level of comfort and the demand on human factors resources (such as workload and mental capacity) or, opposite to that, the risk of stress, overload, or frustration when working with that procedure (10 = best imaginable, 1 = worst imaginable). At this validation phase, values of 7 or above are considered as acceptable. Due to the relatively low number of participants, small differences between the individual ratings should not be over-interpreted. Results are displayed in Figure 5.

It can be seen that baseline II scenario was rated as the best in average by all participants. Only the remote pilots deviate from that because it is most simple and comfortable for them when the aerodrome is reserved for their movement, which is why they rated baseline I the best. In total, the ratings regarding human performance for the segmented standard taxi route procedure are acceptable. Especially for the conventional pilots there seems to be almost no negative impact in terms of human factors / human performance. However, as there are only small differences between most of the individual ratings a more detailed analysis regarding human performance involving different validation methods (e.g. real-time human in the loop simulation) is desirable.

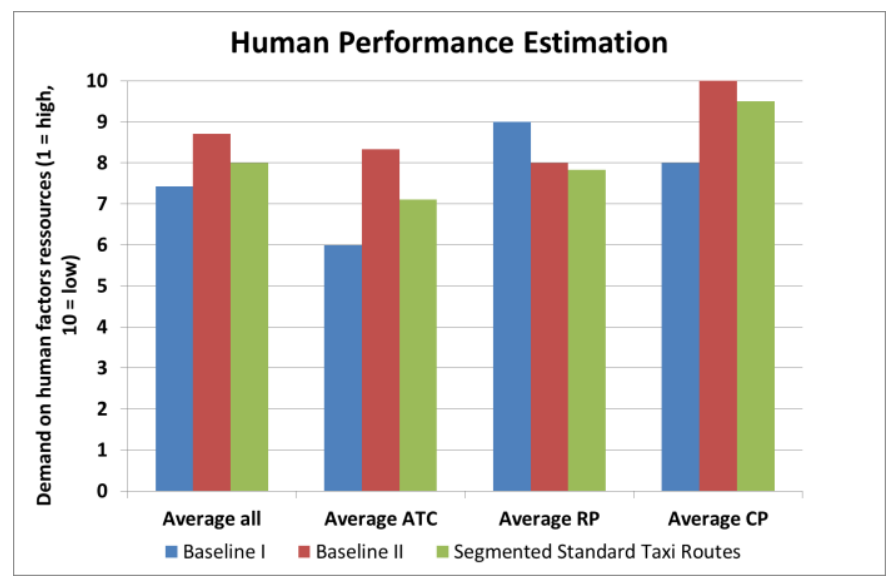

Fig. 5. Results for human performance estimation

\section{E. User preferences}

The workshop participants were also individually asked to state their preferences by giving a score from 0 (least preferred) to 2 (most preferred) regarding baseline I, baseline II and segmented standard taxi routes. Results are displayed in Table 2.

TABLE 2. USER PREFERENCES RESULTS REGARDING BASELINE I, BASELINE II AND SEGMENTED STANDARD TAXI ROUTES (RP $=$ REMOTE PILOTS, CONVP $=$ CONVENTIONAL PILOTS)

\begin{tabular}{|l|l|l|l|}
\hline Participant & $\begin{array}{l}\text { Baseline I } \\
\text { Score }\end{array}$ & $\begin{array}{l}\text { Baseline II } \\
\text { Score }\end{array}$ & $\begin{array}{l}\text { Segmented } \\
\text { Standard Taxi } \\
\text { Route Concept } \\
\text { Score }\end{array}$ \\
\hline ATC1 & 0 & 1 & 2 \\
\hline ATC2 & 0 & 1 & 2 \\
\hline ATC3 & 0 & 2 & 1 \\
\hline RP1 & 0 & 1 & 2 \\
\hline RP2 & 0 & 1 & 2 \\
\hline ConvP1 & 0 & 1 & 2 \\
\hline ConvP2 & 0 & 2 & 1 \\
\hline Total & 0 & $\mathbf{9}$ & $\mathbf{1 2}$ \\
\hline
\end{tabular}

It can be seen that all participants always gave a score of 0 to baseline I. This solution can therefore be seen as the worst imaginable case.

Baseline II already achieved a high level of acceptance and can therefore at least be seen as practical and feasible alternative.

Nevertheless, in total there is a clear preference for the proposed segmented standard taxi route concept. 


\section{DISCUSSION AND OUTLOOK}

The concept proposed in this paper was rated by the experts from different stakeholders (ATC, remote and conventional pilots as well as an ATM expert from DFS) as a very realistic approach which can easily be brought to operation within the next 5 to 10 years. Its greatest benefit compared to baseline I is a significantly higher level of access and equity in mixed manned and unmanned traffic without negatively affecting safety.

The KPAs investigated in this study showed, that baseline II and the new procedure of segmented standard taxi routes show comparable levels of safety, access and equity, interoperability and human performance. Therefore, according to these KPAs, both solutions can be seen as more or less equal and a more detailed analysis involving different validation methods (e.g. real-time human in the loop simulation) is needed to determine the pro's and con's. Additional aspects or KPAs have to be considered. As a first conclusion, baseline II should be chosen whenever the segmented standard taxi route concept is not suitable or not available (backup solution). However, as soon as several RPAS intend to perform ground movements at the same time (e.g. at international airports), the resources needed for the baseline II solution could be enormous compared to using segmented standard taxi routes. In addition to that, the concept of segmented standard taxi routes is basically compatible with fully automatic ground movements of unmanned aerial systems, which is another advantage that also points towards the future.

As the work presented in this paper is equal to a V1 validation according to E-OCVM, a set of fast-time and/or real-time simulations is planned for the $\mathrm{V} 2$ validation phase.

\section{ACKNOWLEDGMENT}

The authors of this paper are very grateful and would like to thank all participants of the validation workshop conducted on $21^{\text {st }}-23^{\text {rd }}$ November 2017 at DLR premises in Cologne. Without their expertise and valuable input this concept would not have reached this state of maturity.

\section{REFERENCES}

[1] European Aviation Safety Agency (EASA), Introduction of a regulatory framework for the operation of unmanned aircraft, 2015, pp. 18-29

[2] International Civil Aviation Organization (ICAO), Annex 11 - Air Traffic Services, July 2001, p. 2-2

[3] International Civil Aviation Organization (ICAO), Annex 14 Aerodromes, Vol. I, July 2013, pp. 5-1 - 5-24

[4] International Civil Aviation Organization (ICAO), Annex 14 Aerodromes, Vol. I, July 2013, pp. 5-69-5-71

[5] International Civil Aviation Organization (ICAO), Annex 2 - Rules of the Air, July 2005, p. APP 1-3

[6] K. Straube, M. Roßbach, B. D. Vieten, K. Hahn, Follow-the-Greens: The Controller's Point of View - Results from a SESAR Real Time Simulation with Controllers, AHFE 2016 Conference, Orlando (FL), July 2016

[7] International Civil Aviation Organization (ICAO), Doc 4444 Procedures for Air Navigation Services - Air Traffic Management, 2007, p. 7-13

[8] DFS Deutsche Flugsicherung GmbH, Manual of Air Traffic Services (MO-ATS), October 2017, p. 14-2

[9] DFS Deutsche Flugsicherung GmbH, Manual of Air Traffic Services (MO-ATS), October 2017 , p. 31-3

[10] EUROCONTROL, European Operational Concept Validation Methodology (E-OCVM), Version 3.0, Vol. I, February 2010, p. 49

[11] D. M. Dehn, Assessing the Impact of Automation on the Air Traffic Controller: The SHAPE Questionnaires, ATC Quarterly, Vol. 16(2), 2008, pp. $127-146$

37th Digital Avionics Systems Conference

September 23-27, 2018 